Nascimento, V.L.Q.; Simonian, L.T.L. A política de ecoturismo no Polo

Belém/Costa Atlântica (PA). Revista Brasileira de Ecoturismo, São Paulo,

v.7, n.3, ago/out 2014, pp.618-645.

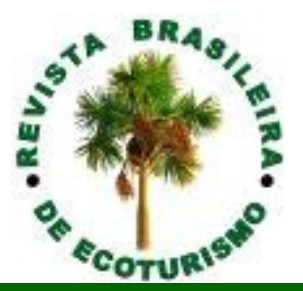

\title{
A política de ecoturismo no Polo Belém/Costa Atlântica (PA)
}

\author{
Ecotourism policy in Belém/Atlantic Coast Pole (PA, Brazil)
}

\author{
Vânia Lúcia Quadros Nascimento, Ligia Terezinha Lopes Simonian
}

\begin{abstract}
RESUMO
O segmento do ecoturismo foi objeto de políticas públicas específicas para o seu desenvolvimento em âmbito nacional e em especial na Amazônia. Com este artigo, objetiva-se analisar a implementação da política pública de ecoturismo para a região Amazônica, com recorte no Programa de Desenvolvimento do Ecoturismo na Amazônia Legal (PROECOTUR), no polo Belém/Costa Atlântica. Busca-se, ainda, analisar a participação dos atores sociais nesse processo bem como a contribuição do Programa para o desenvolvimento sustentável na área em questão. Para a coleta dos dados que subsidiaram este artigo foram realizadas pesquisas bibliográfica, documental - incluindo fotografias e mapas - e pesquisa de campo. Em conclusão, tem-se, entre outros, que o processo de descontinuidade do PROECOTUR ocorreu em razão de fatores de ordem administrativa, política e econômica; que a participação dos atores não ocorreu como previsto, pois os Grupos Técnicos Operacionais (GTO) do polo não foram criados; que o turismo no polo em questão encontra-se pouco estruturado; e que a implementação do Programa não foi monitorada ou avaliada, em momento algum, pela Unidade de Gerenciamento do Programa (UGP) ou pelo Núcleo de Gerenciamento do Programa (NGP)/PROECOTUR-PA.
\end{abstract}

PALAVRAS-CHAVE: Ecoturismo; Políticas Públicas de Ecoturismo; Planejamento; Desenvolvimento; Polo Belém/Costa Atlântica.

\section{ABSTRACT}

The ecotourism segment was the main focus for the development of specific policies at national level and especially in the Amazon. The purpose of this paper is to analyze the implementation of public policies of ecotourism for the Amazon Region, with emphasis on Ecotourism Development Program in the Amazon (PROECOTUR), in the Belem/Atlantic Coast Pole. Another aim is to analyze the participation of social actors in this process, as well as the contribution of this Program for the sustainable development in the area under consideration. In order to compile the data comprised in this article, bibliographical information, documentary research - including photographs and maps - and fieldwork were conducted. In summary, there are, among others, the discontinuity of the PROECOTUR process which occurred due to administrative, political and economic factors; the participation of the actors did not occur as expected, since the Technical Operational Groups (TOG) of the Pole were not created; the aforesaid tourism in this area is poorly structured; and the implementation of the program was not monitored or evaluated, at some point, by the Program Management Unit (PMU) or the Center for Program Management (CPM)/PROECOTUR-PA.

KEYWORDS: Ecotourism; Public Policies of Ecotourism; Planning; Development; Belém/Atlantic Coast Pole. 


\section{Introdução}

A região Amazônica tem sido, ao longo dos tempos, foco da ação governamental em prol de sua ocupação, povoamento e desenvolvimento. Este último pautado principalmente nos princípios da sustentabilidade, conforme demonstra Brasil (2007). Tem sido alvo de atenção, também, por parte da comunidade acadêmica, na qual pesquisadores de áreas diversas têm discutido tal assunto.

Alguns pesquisadores discutem sobre a Amazônia abordando questões teóricas, a exemplo de Costa (2001a). Outros como Costa (2001b) e Simonian (2007a) o fazem considerando as atividades econômicas e as respectivas políticas públicas para o desenvolvimento delas, e não se pode esquecer os anseios e o agir dos atores sociais, direta e indiretamente, nelas envolvidos. Ou, ainda, como Silva et al. (2013, p.230) que estudam a atuação de diferentes elementos sociais, políticos e econômicos "[...] na transformação do espaço amazônico, principalmente a partir da implantação dos grandes projetos de infraestrutura e dos planos governamentais", isso tendo como horizonte temporal a década de 1970 chegando até a atualidade.

Souza, M. (2006a, 2006b) aponta que se devem pensar os atores sociais acima citados atrelados ao seu espaço, este percebido quer como lugar quer como território. Isto de modo que, ao obter qualidade de vida melhor e justiça social maior, eles alcancem 0 desenvolvimento socioespacial, que congrega a questão ambiental e a interação entre os atores sociais no âmbito do espaço. E que toma como base para isso a defesa da autonomia individual e coletiva.

É na esfera desses dois paradigmas de desenvolvimento, o sustentável e o socioespacial, que a atividade turística se destaca como capaz de promover ambos. Em virtude disso, o turismo tem sido objeto de políticas públicas federal, estaduais e municipais. Isto vem acontecendo, segundo Dias (2003), desde a década de 1960, quando o governo federal criou a Empresa Brasileira de Turismo (EMBRATUR) ${ }^{1}$ e instituiu diretrizes para a formulação de uma política nacional de turismo.

Em relação especificamente à Amazônia, o governo federal começou a elaborar políticas públicas de turismo, e ecoturismo também, a partir da década de 1970. Cita-se como exemplo delas o I e o II Plano de Turismo da Amazônia (PTA) e o Programa de Desenvolvimento do Ecoturismo na Amazônia Legal (PROECOTUR) (FIGUEIREDO, S., 1999a; NÓBREGA, 2007). Matus (1989) aponta que se concebeu grande parte dessas políticas de maneira tecnocrática pautada basicamente em aspectos econômicos, não atentando para as carências, possibilidades e particularidades legítimas dos estados da região, e para o pensar e os anseios das populações locais. $\mathrm{Na}$ maioria das vezes, não se atentava, também, para as ações a serem efetivamente realizadas; aos recursos, sobretudo orçamentários, para tanto; e a fonte destes.

É válido ressaltar que o estado do Pará também tem sido alvo de estudos no que tange a atividade turística. Destacam-se, nesse sentido, as pesquisas de Campos (2008), Figueiredo, S. (1999b), Nascimento (2002), Nóbrega (2007), Pinto (2006), Quaresma (2003), entre outras. Tais autores 
analisam a realidade e as possibilidades do turismo e do ecoturismo, considerando a participação dos principais atores sociais envolvidos, enquanto atividades promotoras de desenvolvimento sustentável. Há que se enfatizar que a participação dos atores, principalmente na implementação das políticas públicas, tem culminado com a criação de instâncias de governança, a exemplo dos conselhos municipais, para as quais, na maioria das vezes, eles não estão preparados para tomar parte.

Nesse contexto, com este artigo apresenta-se um estudo da implementação das políticas públicas de ecoturismo para a Amazônia Legal, com recorte no PROECOTUR. Analisa-se como o processo de implementação do PROECOTUR no polo Belém/Costa Atlântica, estado do Pará (Amazônia Oriental), foi desenvolvido e as razões de sua descontinuidade. Para tanto, partiu-se de uma abordagem neoinstitucionalista e dos preceitos dos paradigmas de desenvolvimento sustentável e socioespacial.

A opção por tal objeto deveu-se à necessidade de priorização do ecoturismo no âmbito das políticas públicas federal e estadual de turismo, dada a vocação natural do Brasil e, notadamente, da Amazônia. Deveu-se, também, ao fato de que o PROECOTUR foi pensado especificamente para a Amazônia Legal. E, ainda, por ele possuir recursos financeiros definidos para a sua implementação e por apresentar um viés eminentemente participativo.

A área de estudo compreendeu a capital do estado além de nove municípios pertencentes ao Nordeste paraense. O período analisado datou de 2001, quando o polo Belém/Costa Atlântica passou a integrar o PROECOTUR, até dezembro de 2008. Buscou-se: identificar os fatores que contribuíram para a descontinuidade no processo de implementação do PROECOTUR; analisar a participação dos atores sociais ${ }^{2}$ integrantes do polo Belém/Costa Atlântica no processo de implementação do PROECOTUR; identificar as contribuições ou não do Programa para o desenvolvimento sustentável dos municípios desse polo; conhecer de que modo o setor turístico está estruturado no polo Belém/Costa Atlântica; e analisar a constituição, objetivos, competência e atuação dos Grupos Técnicos Operacionais (GTO) do PROECOTUR no polo Belém/Costa Atlântica.

O estudo realizado constituiu-se, conforme o disposto por Chizzotti (1991), Dencker (2001), Neves (1996) e Vidal (2006), em uma pesquisa qualitativa, pautada no paradigma sócio-crítico ou dialético ou teoria crítica. Quanto à abordagem, ainda no pensar de tais autores, os dados foram apresentados descritivamente. Em relação aos procedimentos técnicos, segundo Chizzotti (1991), Neves (1996) e Yin (2005), fez-se um estudo de caso. Considerou-se, ainda, o pensar de Oliveira, R. (1996) e Simonian (2007b, 2005) no que se refere à utilização de algumas habilidades e de imagens para a realização da pesquisa e consequente produção do conhecimento, pautados nos preceitos da eficiência e da ética na pesquisa.

A pesquisa realizada para a redação deste artigo foi composta de levantamentos bibliográficos, documentais - incluindo fotografias, mapas - e pesquisa de campo e foi desenvolvida em quatro fases. A primeira fase foi 
constituída de pesquisa bibliográfica sobre os temas desenvolvimento sustentável e socioespacial; políticas públicas, ênfase na de ecoturismo; turismo, especificamente o segmento de ecoturismo; e participação. Realizou-se junto aos órgãos e instituições governamentais públicas e privadas, bem como a entidades direta e indiretamente ligadas ao turismo. Foi constituída, também, de pesquisa documental, baseada em materiais oficiais a exemplo dos relatórios e contratos referentes ao PROECOTUR.

A segunda fase da pesquisa foi a coleta dos dados empíricos, durante a pesquisa de campo. Ocorreu a partir da voz ou discurso dos atores sociais envolvidos no processo de implementação do PROECOTUR, bem como da observação da realidade in loco, no polo em análise. Ouviram-se gestores públicos de turismo, integrantes de órgãos e instituições governamentais públicas e privadas, representantes da iniciativa privada e da sociedade civil organizada.

Com as informações coletadas nesta segunda fase aprofundou-se e detalhou-se a ideia geral, construída na primeira fase da pesquisa, sobre o objeto de estudo. Utilizou-se, como técnica de levantamento de dados, entrevistas semiestruturadas. Foram realizadas trinta e seis entrevistas, entre os meses de abril e agosto de 2008. A terceira fase consistiu na análise e interpretação das evidências coletas (DENCKER, 2001; OLIVEIRA, R. 1996; YIN, 2005). A quarta foi a elaboração do trabalho escrito.

Neste artigo tem-se, além desta, mais seis seções. A seção dois traz algumas considerações teóricas sobre planejamento; desenvolvimento sustentável e socioespacial; políticas públicas de ecoturismo; e participação. $\mathrm{Na}$ seção três, o polo Belém/Costa Atlântica é contextualizado e caracterizado brevemente, enfatizando os aspectos fisicoterritoriais, socioeconômicos e turísticos.

$\mathrm{Na}$ seção quatro, discute-se o processo de concepção e formulação do PROECOTUR e sua implementação no estado do Pará. Na seção cinco, aprofunda-se a discussão iniciada na quarta seção, enfatizando-se a participação dos atores sociais no processo. Na seção seis, analisam-se as contribuições ou não do Programa para o desenvolvimento sustentável e socioespacial do Belém/Costa Atlântica. Na última seção são apresentadas algumas considerações finais e perspectivas futuras, concluindo a análise do processo de implementação do PROECOTUR.

Ressalta-se que este estudo consiste na análise da implementação de uma política pública. O que é uma prática ainda recente e pouco usual, sobretudo em se tratando da atividade turística e, especialmente, do ecoturismo. Isto uma vez que as políticas públicas de turismo são elaboradas e implementadas, tanto na esfera federal quanto estadual, a cada governo que toma posse. Porém chega-se a um determinado momento no qual não se tem mais informações sobre a implementação delas. Foi no intuito de amenizar essa carência que este artigo foi elaborado. 


\section{Perspectivas teóricas: planejamento, desenvolvimento, políticas públicas de ecoturismo e participação}

O agravamento da questão ambiental aliado a outros fatores a exemplo da crise do petróleo; o relatório, Os Limites do Crescimento, do Clube de Roma (1972); e a Conferência das Nações Unidas sobre o Homem e o Meio Ambiente (Estocolmo - Suécia, 1972) levaram a humanidade, em meados do século $X X$, a rever suas ações e a ameaça destas para a sua própria existência (BUARQUE, 2006; SACHS, 1993). Com isso, o modelo de desenvolvimento, até então utilizado, passou a ser redefinido.

Com base nesse pensar, Sachs (1993, p.30; grifo do autor) propõe o conceito de "[...] desenvolvimento socioeconômico equitativo, ou ecodesenvolvimento", que se tornou gênese de estudos posteriores, sendo o de maior destaque 0 da Comissão Mundial para o Meio Ambiente e Desenvolvimento (CMMAD) denominado "Our common future"3 (Nosso Futuro Comum). É nele que surge o termo desenvolvimento sustentável, definido como "[...] aquele que responde às necessidades do presente de forma igualitária, mas sem comprometer as possibilidades de sobrevivência e prosperidade das gerações futuras" (CMMAD, 1987 apud BUARQUE, 2001, p.68). Pode-se abstrair, a partir dessa definição, que 0 desenvolvimento sustentável é um processo que reúne os problemas socioeconômicos e ecológicos mundiais, primando pela utilização consciente das espécies e ecossistemas e pela responsabilidade frente às gerações futuras.

Por outro lado, Souza, M. (2006a, p.60-61; grifo do autor) concebe desenvolvimento como "[...] uma mudança social positiva [...]", cujo conteúdo é definido considerando "[...] os desejos e expectativas dos grupos sociais concretos, com seus valores culturais próprios e suas particularidades histórico-geográficas". É o que ele denomina desenvolvimento socioespacial. Isto posto que, para ele, sociedade e espaço são indissociáveis.

No Brasil, também a partir de 1970, a discussão acima se fez presente e ecoou, entre outros, na formulação e implantação da Política Nacional de Meio Ambiente, em 1981; e na criação, em 1992, do Ministério do Meio Ambiente (MMA). Porém a alteração decisiva do paradigma de desenvolvimento em voga no país ocorreu com a realização da Conferência das Nações Unidas sobre o Meio Ambiente e Desenvolvimento (CNUMAD), no Rio de Janeiro em 1992, conhecida como Eco-92 ou Conferência da Terra.

No que concerne à região Amazônica, as discussões realizadas na Eco-92 levaram ao questionamento do paradigma de desenvolvimento eminentemente deletério imposto a ela. Este passa então de exclusivamente desenvolvimentista para o ecológico e da preservação ambiental. A se pensar a partir de Costa (2001b), teria que cooperar para a produção da equidade social, a formação e adoção de tecnologias adequadas à realidade local e redução das pressões sobre a biodiversidade.

Para tanto, é necessário um estilo de governo alicerçado nos princípios da democracia participativa. Neste estilo, o Estado, sociedade civil organizada, setor privado e as comunidades locais agem conjuntamente e têm poder de decisão, cabendo ao primeiro induzir e gerenciar parte dessas 
transformações. Tem-se então que o modelo de desenvolvimento para a Amazônia incorpora os preceitos tanto do desenvolvimento sustentável quanto do socioespacial. É nesse contexto que o turismo é proposto, especialmente 0 segmento do ecoturismo, como alternativa para 0 desenvolvimento dessa região.

O turismo é, na definição da Organização Mundial do Turismo (OMT) (apud OLIVEIRA, A., 2005, p.36), "[...] o fenômeno que ocorre quando um ou mais indivíduos se trasladam a um ou mais locais diferentes de sua residência habitual por um período maior que 24 horas e menor que 180 dias, sem participar dos mercados de trabalho e capital dos locais visitados". Com base nessa definição, Petrocchi (2001, p.73) aponta que o planejamento do turismo está relacionado com o "[...] planejamento econômico de um país". Portanto, planeja-se o desenvolvimento do mesmo, buscando contribuir para melhoria econômica dos países que seguem tal pensamento.

Na década de 1990, segundo a concepção de Cruz (2002, p.57) na qual "[...] o turismo é a única atividade econômica em que o consumo do espaço constitui sua razão de ser", o planejamento do turismo no Brasil com enfoque na valorização humana e na preservação ambiental e cultural substituiu o desenvolvimentista, meramente econômico. Inicialmente esse planejamento seguia, segundo Petrocchi (2001), uma abordagem regional, expressa no Programa Nacional de Municipalização do Turismo (PNMT) que o pensava com foco nos municípios. Todavia, a partir de 2004, a fronteira municipal é transposta. Passa-se, de acordo com Brasil (2004), a trabalhar a região turística apregoada pelo Programa de Regionalização do Turismo (PRT) - Roteiros do Brasil.

$\mathrm{Na}$ Amazônia, o planejamento do turismo data da década de 1970, com o lançamento do I PTA, em 1977, pela então Superintendência do Desenvolvimento da Amazônia (SUDAM). Outra ação ocorre, segundo Figueiredo, S. (1999a), em 1992 com o II PTA. Nesse plano, os pontos principais são o ecoturismo e o detalhamento de polos de desenvolvimento, conformando, mais uma vez, o enfoque regional, apontado por Petrocchi (2001), no planejamento do turismo. A partir de então, o conceito de polo passa a permear o planejamento do desenvolvimento da atividade nessa região.

Por fim, os últimos atos de planejamento do desenvolvimento da atividade turística de âmbito nacional, para a Amazônia, datam de 1997, quando foram estabelecidas as estratégias para o desenvolvimento do segmento do ecoturismo na região (FIGUEIREDO, S., 1999a). Nelas considerou-se o conceito de polos e foram selecionados polos de ecoturismo, sendo um em cada estado amazônico (BRASIL, 1997). Tais estratégias embasaram a formulação do PROECOTUR que foi planejado, por seu turno, para ser desenvolvido nos polos selecionados.

Vale destacar que o ajuste do cenário acima descrito implica, segundo Buarque (2006) e Castro (2001), na redefinição do papel do Estado e na formulação e implementação das políticas públicas. Estas, agora, advêm de um processo de planejamento do desenvolvimento estratégico, situacional e participativo (BENI, 2006; BUARQUE, 2006; DIAS, 2003; MATUS, 1989; 
PETROCCHI, 2001). O Estado, a iniciativa privada e a sociedade civil passam a compartilhar a formulação e implementação das políticas públicas. Ao primeiro cabe, não mais definir, mas induzir e fomentar tal processo; e aos demais, atuar efetivamente representando e defendendo seus interesses no jogo do poder da tomada de decisões.

Simonian (2000, p.14) assevera que:

[...] um conceito de políticas públicas implica propostas, planos, metas definidas a partir de estruturas de poder que podem incluir o Estado e seus representantes mais diretos, destinados ao ambiente, recursos naturais e à sociedade, onde e com quem são implementados.

É nesse contexto que a atividade turística passa a ser objeto de políticas públicas no Brasil e na Amazônia. Isto posto que "[...] um melhor desempenho econômico do turismo no Brasil depende das políticas urbanas e regionais que venham a ser levada a cabo no país" (CRUZ, 2002, p.35). Assim, é responsabilidade do poder público, na visão de Petrocchi (2001), a criação de um ambiente favorável à atividade turística, sendo imperiosas para tanto as políticas governamentais.

Em se tratando do Brasil, em virtude de suas características naturais, um dos segmentos do turismo que mais se destaca é o ecoturismo. Este é conceituado nas "Diretrizes para uma Política Nacional de Ecoturismo" como:

[...] um segmento da atividade turística que utiliza, de forma sustentável, o patrimônio natural e cultural, incentiva sua conservação e busca a formação de uma consciência ambientalista através da interpretação do ambiente, promovendo o bem-estar das populações envolvidas (BRASIL, 1994, p. 19).

Com base nessa conceituação, que agrega a utilização dos recursos naturais e culturais a preservação dos mesmos, tem-se que a região brasileira que mais atrai ecoturistas é a Amazônica. Todavia, tal segmento é realizado desordenadamente, sem qualquer tipo de controle ou normas reguladoras, estimulado pela oportunidade mercadológica e pelo idealismo quase místico que envolve essa região, despertando nos indivíduos o desejo de conhecê-la e preservá-la.

Com vistas a solucionar tal situação, o Governo Federal formulou políticas públicas específicas. Assim sendo, objetivando "[...] desenvolver e dinamizar os polos de ecoturismo selecionados no âmbito dos Estados da Amazônia Legal' (BRASIL, 1997, p.8), uma delas está materializada no documento Estratégias para o Desenvolvimento Integrado do Ecoturismo na Amazônia Legal (BRASIL, 1997), datado de 1997. É nele que constam as contribuições para a definição das ações do PROECOTUR.

Convém destacar que após o desenho e a formulação, as políticas públicas concretizam-se em planos, programas e projetos que, em conformidade com o disposto por Souza, C. (2007, 2006), são subordinados a sistemas de acompanhamento e avaliação. É o chamado ciclo das 
políticas, que consiste na: decisão, formulação, implementação, monitoramento e avaliação. Faria (2005, p.97-98) define avaliação como:

[...] a) atividade destinada a aquilatar os resultados de um curso de ação cujo ciclo de vida se encerra; b) a fornecer elementos para o desenho de novas intervenções ou para o aprimoramento de políticas e programas em curso; e c) como parte da prestação de contas e da responsabilidade dos agentes estatais, ou seja, como elemento central da accountability ${ }^{4}$.

Todavia, conforme apontam Faria (2005), Frey (2000), Silva (2001) e Souza, C. $(2007,2006)$, há que se considerar algumas questões teóricometodológicas no que concerne à análise/avaliação das políticas públicas. Essas questões referem-se aos modelos de formulação da política; ao processo da política e os sujeitos sociais envolvidos, considerando suas racionalidades; e a avaliação propriamente dita, com seus modelos, métodos e técnicas. Outro ponto a ser considerado, segundo o pensar de Grasso (2003), Leviton (2003) e Sridharan (2003), diz respeito ao uso que será dado aos resultados obtidos na avaliação. Esta somente será útil se gerar melhorias sociais.

Ressalta-se que este estudo foi executado sob um ponto de vista neoinstitucionalista, pautado nos preceitos defendidos por Hall e Taylor (2003) e Théret (2003). Isto por considerar, na compreensão da ação dos indivíduos e suas manifestações coletivas, o papel desempenhado pelas instituições na mediação entre as estruturas sociais e comportamentos individuais e na determinação dos resultados sociais e políticos. Com base em tais autores, este estudo considerou o neoinstitucionalismo histórico e o sociológico. O primeiro em virtude do destaque aos temas do poder e dos interesses. E o segundo, por conta do papel das normas e práticas associadas à cultura e às instituições.

Outro conceito abordado neste estudo foi o de participação ${ }^{5}$. Esta, segundo Buarque (2006) e Matus (1989), é indispensável para o desenvolvimento sustentável. Para tais autores a participação da sociedade civil afiança a efetividade e eficácia do poder público, garantindo com isso, uma governança boa e democrática. Bordenave (2002, p.16) conceitua participação como "[...] o caminho natural para o homem exprimir sua tendência inata de realizar, fazer coisas, afirmar-se a si mesmo e dominar a natureza e o mundo". Já Demo (1988) defende que ela é uma conquista sempre em construção. Em que pese a participação pareça ser uma tarefa fácil, é complexa, sendo necessário preparo e maturidade para desempenhá-la.

Beni (2006), Dias (2003) e Petrocchi (2001) asseveram que para a atividade turística é de grande importância que haja a participação de todos os atores sociais envolvidos. Isto uma vez que o efeito multiplicador do turismo abrange segmentos, setores e instituições/entidades direta e indiretamente a ela ligados, podendo ou não estar territorialmente incluídos na área planejada. No que tange ao planejamento do turismo, a participação assume papel de destaque maior quando o mesmo alicerça-se nos paradigmas do desenvolvimento sustentável e do socioespacial. 
Os graus e/ou níveis de participação são definidos por Bordenave (2002). Os primeiros são: a informação, a consulta facultativa, consulta obrigatória, elaboração/ recomendação, cogestão, delegação e autogestão. Entre eles o menor é a informação e o maior é a autogestão. Outra classificação dos graus de participação popular ${ }^{6}$ é apresentada por Souza, M. (2006a, 2006b). Para ele, a mesma é posta como base na mensuração da autonomia e, opostamente, da heteronomia e compreende oito categorias: coerção, manipulação, informação, consulta, cooptação, parceira, delegação de poder e autogestão.

Ainda, note-se que o grau de participação mais baixo está na coerção, onde a autonomia individual e coletiva é mínima e a heteronomia é máxima. E que o grau mais alto está na autogestão, na qual a autonomia individual e coletiva é máxima e a heteronomia é mínima. Foi embasado nesse arcabouço teórico que se produziu este artigo.

\section{Polo Belém/Costa Atlântica: aspectos fisicoterritoriais, socioeconômi- cos e turísticos}

No âmbito do PROECOTUR, o polo Belém/Costa Atlântica incorpora a capital paraense Belém e os municípios de Curuçá, Marapanim, Maracanã, São João de Pirabas, Salinópolis, Tracuateua, Bragança, Augusto Corrêa e Viseu (Figura 1). A história do polo remete à formação histórica dos municípios que o compõem, ressaltando-se que a ocupação deles teve início no século XVII, com a fundação de Belém, e finalizou na última década do século $X X$, com a criação e instalação de Tracuateua. Os municípios desse polo pertencem às mesorregiões Metropolitana de Belém e do Nordeste paraense. A partir de Belém, o acesso aos demais municípios é realizado por via terrestre, pela rodovia BR-316.

A Companhia Paraense de Turismo (PARATUR) (PARÁ, 2004) aponta que os climas predominantes no polo são o tropical superúmido e o equatorial quente e úmido. A temperatura média mensal é de $25^{\circ} \mathrm{C}$, com máxima de até $36^{\circ} \mathrm{C}$ e mínima alcançando $18^{\circ} \mathrm{C}$. A umidade relativa do ar compreende médias mensais oscilantes entre $68,5 \%$ a $96,4 \%$. A precipitação média anual varia entre $2.100 \mathrm{~mm}$ e $2.834 \mathrm{~mm}$ ao ano.

Ainda em conformidade com a PARATUR, em termos geológicos, verifica-se a presença de sedimentos qualificados como: quaternários atuais e subatuais, terciários e suíte intrusiva proterozóico inferior. Os relevos são caracterizados pelos baixos platôs e planícies fluviomarinhas. A vegetação existente classifica-se em seis formações bem definidas: Floresta Equatorial Subperenifólia, Floresta Equatorial Hidrófila e Higrófila de Várzea, Campos Equatoriais Higrófilos de Várzea, Formações de Praias, Dunas e Manguezais. A hidrografia é composta por rios, lagos, igarapés, muitos dos quais deságuam no oceano Atlântico. 

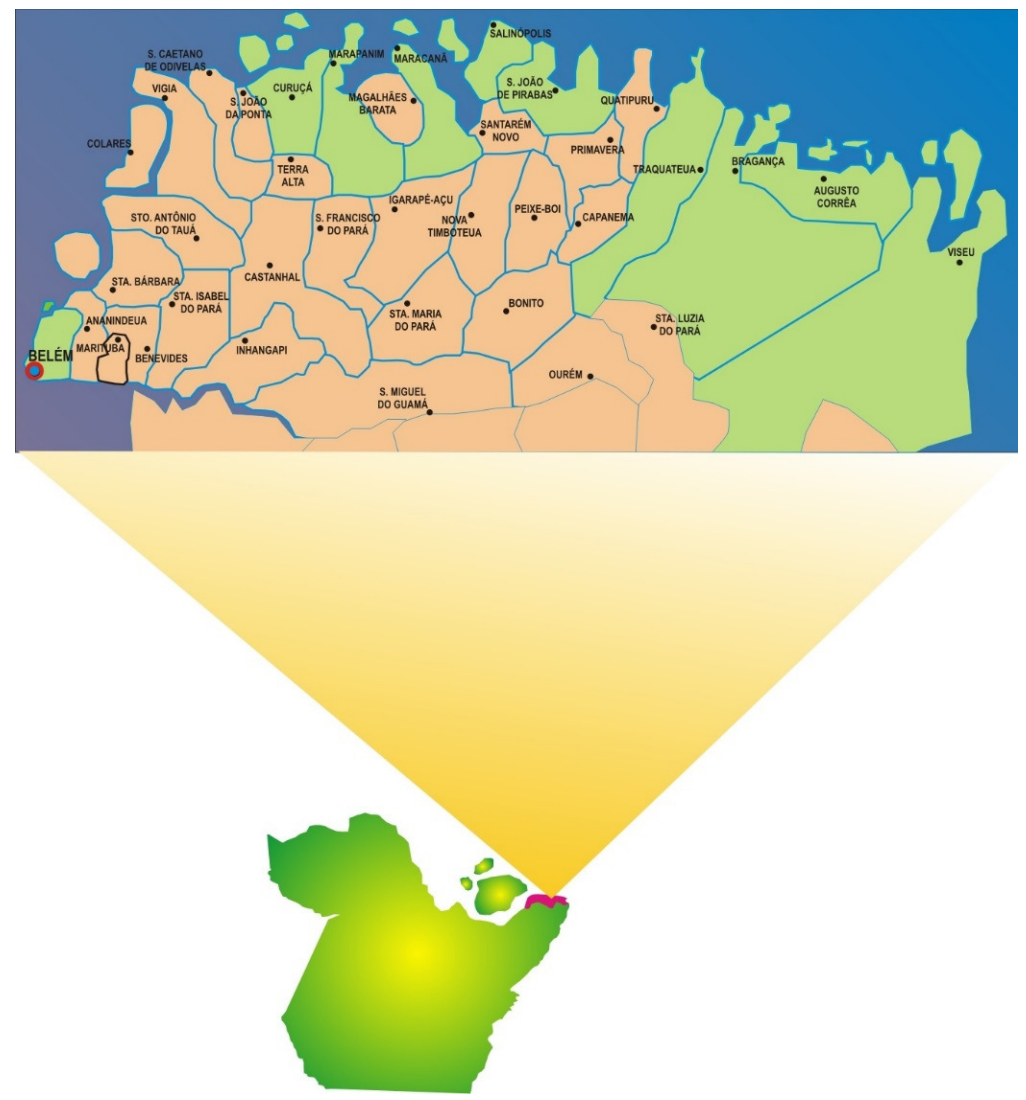

Figura 1: Localização e composição do polo Belém/Costa Atlântica. Fonte: Elaborado por Genildo Mota (2008).

Figure 1: Location and composition of the Belém/Atlantic Coast pole Source: Prepared by Genildo Mota (2008).

Em 2001, quando teve início a implementação do PROECOTUR no polo Belém/Costa Atlântica, este possuía 1.610.619 habitantes distribuídos em $13.178 \mathrm{~km}^{2}$ de área territorial. Do total da população, 1.434 .831 residiam na zona urbana e 175.788 na rural, segundo dados do Censo Demográfico, realizado em 2000 (BRASIL, 2000) (Tabela 1). À exceção de Belém, Bragança, Salinópolis e São João de Pirabas, a maioria da população dos demais municípios residia na zona rural. A densidade demográfica do polo era de $122,21 \mathrm{hab} . / \mathrm{km}^{2}$ e a taxa de urbanização era de $89,08 \%$ (Tabela 1). Do total de habitantes do polo, $39,77 \%$ vivia abaixo da linha da pobreza, sendo o Índice de Desenvolvimento Humano (IDH) médio de 0,672.

Tabela 1: Área, população (total e por situação da unidade domiciliar), densidade, urbanização do polo Belém/Costa Atlântica - 2001.

Table 1: Area (total and situation of the household) population density, urbanization of the Belém/Atlantic Coast pole - 2001.

\begin{tabular}{|c|c|c|c|c|c|c|}
\hline & \multirow{2}{*}{$\begin{array}{l}\text { Área } \\
\left(\mathrm{km}^{2}\right)\end{array}$} & \multicolumn{3}{|c|}{ População (hab.) } & \multirow{2}{*}{$\begin{array}{l}\text { Densidade } \\
\left(\mathbf{h a b} / \mathbf{k m}^{2}\right)\end{array}$} & \multirow{2}{*}{$\begin{array}{c}\text { Taxa de } \\
\text { Urbanização } \\
(\%)\end{array}$} \\
\hline & & Total & Urbana & Rural & & \\
\hline $\begin{array}{l}\text { Polo } \\
\text { Belém/Costa } \\
\text { Atlântica }\end{array}$ & 13178,30 & 1610619 & 1434831 & 175788 & 122,21 & 89,08 \\
\hline
\end{tabular}

Fonte: Brasil (2000).

Source: Brasil (2000). 
O polo apresentava, em 2001, rendimento médio mensal de $R \$$ 180,87 (cento e oitenta reais e oitenta e sete centavos) e rendimento médio da população ocupada (todos os trabalhos) era de $R \$ 477,01$ (quatrocentos e setenta e sete reais e um centavo). O Produto Interno Bruto (PIB) era de $\mathrm{R} \$$ 5. 954.954,00 (cinco milhões, novecentos e cinquenta e quatro mil e novecentos e cinquenta e quatro reais) e o PIB per capita de $\mathrm{R} \$ 3.697,00$ (três mil, seiscentos e noventa e sete reais). A estrutura produtiva do polo estava alicerçada no setor terciário da economia (60,56\%). A seguir vinha 0 setor primário $(28,62 \%)$. E, por fim, o setor secundário $(10,80 \%)$. As informações acima podem ser melhor visualizadas na Tabela 2.

Tabela 2: Rendimento médio mensal, rendimento médio da população ocupada (todos os trabalhos), Produto Interno Bruto (PIB) a preço de mercado corrente, PIB Per Capita a preço de mercado corrente e Estrutura produtiva do polo Belém/Costa Atlântica - 2001.

Table 2: Average monthly income, average income of the employed population (all jobs), Gross Domestic Product (GDP) at current market prices, GDP Per Capita at current market prices and productive structure of the Belém/Atlantic Coast pole -2001 .

\begin{tabular}{|c|c|c|c|c|c|c|c|}
\hline & \multirow{2}{*}{$\begin{array}{c}\text { Rendimento } \\
\text { Médio } \\
\text { Mensal (R\$ } \\
1,00) \\
\text { Total } \\
\end{array}$} & \multirow{2}{*}{$\begin{array}{c}\begin{array}{c}\text { Rendimento } \\
\text { Médio }\end{array} \\
\text { Total }\end{array}$} & \multirow{2}{*}{$\begin{array}{c}\text { PIB } \\
\text { (R\$ mil) }\end{array}$} & \multirow{2}{*}{$\begin{array}{c}\text { PIB Per } \\
\text { Capita } \\
\text { (Valores } \\
\text { Constantes } \\
\text { R\$) }\end{array}$} & \multicolumn{3}{|c|}{ Estrutura Produtiva } \\
\hline & & & & & $\begin{array}{c}\text { Agropec. } \\
(\%)\end{array}$ & $\begin{array}{l}\text { Ind. } \\
(\%)\end{array}$ & $\begin{array}{c}\text { Serv. } \\
(\%)\end{array}$ \\
\hline $\begin{array}{l}\text { Polo } \\
\text { Belém/ } \\
\text { Costa } \\
\text { Atlântica }\end{array}$ & 180,87 & 477,01 & 5954954 & 3697 & 28,62 & 10,80 & 60,56 \\
\hline
\end{tabular}

Fonte: Brasil (2000).

Source: Brasil (2000).

Em relação aos aspectos turísticos, o polo Belém/Costa Atlântica apresentava, na época do início da implementação do PROECOTUR em 2001, atrativos enquadrados nas categorias natural, histórico-cultural, manifestações culturais, realizações técnicas e científicas contemporâneas e, por fim, acontecimentos programados (PARÁ, 2004). Como o objeto do PROECOTUR era o ecoturismo, os atrativos naturais foram considerados como prioritários ou primários e os demais, como complementares ou secundários. Os atrativos da categoria natural foram identificados em todos os dez municípios do polo, como por exemplo, os demonstrados na Figura 2.

A PARATUR (PARÁ, 2004) aponta que, em termos de infraestrutura turística (equipamentos e serviços turísticos), o polo detinha 159 meios de hospedagem, totalizando 3699 unidades habitacionais e 7474 leitos. Contava com 185 estabelecimentos de serviços de alimentação; 41 estabelecimentos de agenciamento e transporte turístico (dos quais 40 estavam localizados em Belém); 10 instalações para eventos; 28 estabelecimentos de entretenimento. Dispunha, ainda, de um estabelecimento enquadrado na categoria outros (tais como locadoras de veículos, terminal turístico fluvial). 


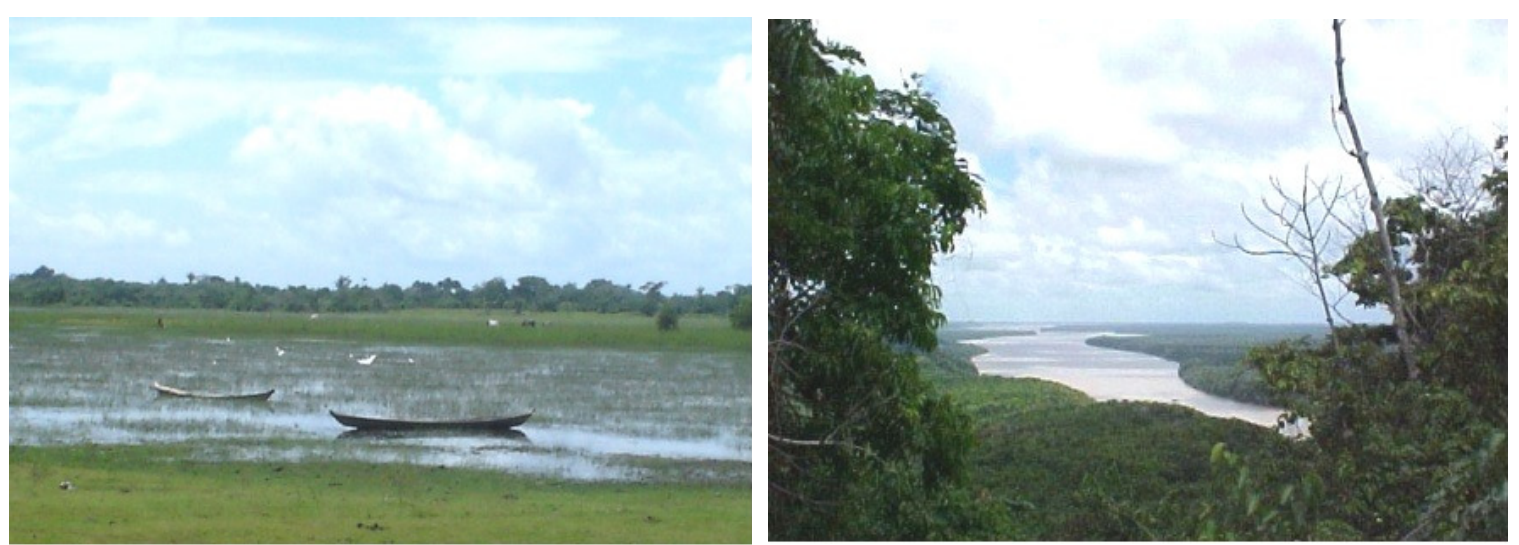

Figura 2: Atrativos turísticos naturais do polo Belém/Costa Atlântica - 2001.

Fonte: Vânia L. Q. Nascimento (2007).

Figure 2: Natural tourist attractions of the Belém/Atlantic Coast pole - 2001.

Source: Vânia L. Q. Nascimento (2007).

E no que tange a infraestrutura de apoio turístico, o polo possuía acesso através de rodovias federal e estaduais. Apresentava sistema de transporte de passageiros via terrestre; sistema de comunicação, telefonia fixa, estações de rádio e repetidoras de emissoras de televisão da capital, acesso a internet mesmo que precário; e sistema de segurança pública. Além disso, os sistemas médico-hospitalar e educacional possuíam estabelecimentos públicos e privados.

A gestão pública do turismo na maioria dos municípios do Belém/Costa Atlântica estava a cargo de uma secretaria ou departamento municipal de turismo. A totalidade dos municípios detinha inventário turístico elaborado pela PARATUR, exceto o de Belém que foi elaborado pela Companhia de Turismo de Belém (BELÉMTUR). Belém era o único município que possuía plano de desenvolvimento turístico, mesmo em versão preliminar. Excluindo-se Curuçá, São João de Pirabas e Maracanã, os demais municípios possuíam Conselho Municipal de Turismo criado por lei municipal, conforme preconizava o PNMT.

\section{PROECOTUR: da formulação à implementação no Pará}

O processo de construção do PROECOTUR perdurou por quatro anos, de 1995 a 1999, iniciando-se com a transferência da responsabilidade pela política de ecoturismo e pela constituição do Grupo Técnico de Coordenação do Ecoturismo para a Amazônia Legal (GTC-Amazônia), do Ministério da Indústria, Comércio e Turismo (MICT) para o MMA. Nesse período foi elaborada a carta consulta que o Ministério do Planejamento, Orçamento e Gestão (MPOG) encaminhou ao Banco Interamericano de Desenvolvimento (BID). Essa carta foi aprovada pelo BID em 27 de outubro de 1999, porém o contrato de empréstimo foi assinado somente em 08 de agosto de 2000, sob o número 1216/OC-BR.

O objetivo do PROECOTUR era, conforme consta no contrato: 
[...] promover o desenvolvimento sustentável do ecoturismo na Amazônia Legal, criando um contexto apropriado e as condições necessárias, incluindo investimentos essenciais, que permitam preparar os Estados do Acre, Amapá, Amazonas, Maranhão, Mato Grosso, Pará, Rondônia, Roraima e Tocantins para administrarem de forma eficiente áreas ecoturísticas selecionadas. (BID, 2000, anexo A, p.1).

E ele estava estruturado em três componentes: planejamento do ecoturismo na Amazônia Legal; gerenciamento do ecoturismo nas áreas selecionadas; e fortalecimento do segmento ecoturístico. O programa foi orçado em US\$13.800.000,00 (treze milhões e oitocentos mil dólares). Desse quantitativo, US $\$ 11.000 .000,00$ (onze milhões de dólares) seriam oriundos do BID, US $\$ 2.670 .000,00$ (dois milhões e seiscentos e setenta mil dólares) do governo federal e US $\$ 130.000,00$ (cento e trinta mil dólares) distribuídos entre os estados amazônicos.

A gestão do PROECOTUR estava sob a égide da Unidade de Gerenciamento do Programa (UGP), constituída no âmbito do MMA. Em cada estado da Amazônia seria instituído o Núcleo de Gerenciamento do Programa (NGP), responsável pela co-execução do PROECOTUR, e o Grupo de Assessoramento (GTC-Estadual). E, em cada município dos polos contemplados, seriam criados os Grupos Técnicos Operacionais (GTO).

A execução do Programa foi pensada em duas fases:

[...] fase de pré-investimentos: com prazo de implementação de até três anos (início em agosto de 2000), com objetivo de verificar a viabilidade técnica, ambiental, social e econômica do ecoturismo na Amazônia;

fase de investimentos: com prazo de implementação de três anos e concentrará os recursos disponíveis nos polos de ecoturismo selecionados pelos estados participantes (BRASIL, 2002, p. 38, grifo no original).

Convém destacar que a vigência do contrato foi prorrogada por duas vezes. A primeira estendeu o prazo final de 2003 para 2006; e a segunda prorrogou de 2006 para 2007. Em fins de 2007, o MMA solicitou mais uma preventiva até março de 2008, para que fossem realizadas as últimas ações que estavam pendentes.

No decorrer desse processo houve cancelamento de recursos em dois momentos. Um em janeiro de 2005, no valor de US\$ 4.491.915,00 (quatro milhões, quatrocentos e noventa e um mil e novecentos e quinze dólares); e outro em novembro do mesmo ano, cujo montante foi de US\$ 2.171.251,00 (dois milhões, cento e setenta e um mil e duzentos e cinquenta e um dólar). Em suma, do recurso inicial de US\$13.800.000,00 (treze milhões e oitocentos mil dólares) foram cancelados US $\$ 6.663 .166,00$ (seis milhões, seiscentos e sessenta e três mil e cento e sessenta e seis dólares). 
A se considera o pensar de Buarque (2006) e o de Matus (1989), temse que o desenho e a formulação do PROECOTUR foram alicerçados em um processo de planejamento do desenvolvimento estratégico, situacional e participativo. E, conforme defendem Figueiredo, A. (1997), Ruediger e Riccio (2005), Souza, M. (2006a, 2006b), o alcance do bem comum por esse programa pretendido agregado a mais justiça social e melhor qualidade de vida é incumbência compartilhada e corresponsabilizada por todos os atores sociais envolvidos no processo. Pode-se afirmar que o arcabouço teórico que embasou o Programa alicerçou-se nos preceitos tanto do desenvolvimento sustentável quanto do socioespacial.

No Pará, inicialmente, a gestão do PROECOTUR ficou sob a responsabilidade da Secretaria de Estado de Ciência, Tecnologia e Meio Ambiente (SECTAM), que através da Portaria $n^{\circ}$. 399, datada de 12 de julho 1999, criou o NGP/PROECOTUR-PA. Foi esse Núcleo que propôs, além do polo Tapajós como prioritário para o PROECOTUR, a inclusão de outros dois: o Marajó e o Belém/Costa Atlântica (PARÁ, 1999). Para tanto, houve uma grande articulação que contou com a participação de representantes da iniciativa pública, liderados pelo NGP/PROECOTUR-PA; da iniciativa privada e da sociedade civil paraense.

O polo Belém/Costa Atlântica congregaria, de início, 12 municípios: Abaetetuba, Augusto Corrêa, Barcarena, Belém, Bragança, Curuçá, Maracanã, Marapanim, Salinópolis, São João de Pirabas, Vigia e Viseu (PARÁ, 1999). Porém, esta configuração foi alterada. Foram retirados os municípios de Abaetetuba, Barcarena e Vigia, e o de Tracuateua foi inserido, em virtude da proximidade entre esses municípios e do indicativo para a criação de unidade de conservação (UC), que em Tracuateua seria uma Reserva Extrativista (RESEX) Marinha. Foi pautado nessa nova configuração $^{7}$ do polo que o PROECOTUR começou a ser implementado no Pará.

Ressalva-se que, para a implementação do Programa no estado do Pará, foram firmados vários convênios entre o MMA, através da Secretaria de Coordenação da Amazônia (SCA), e o governo do Pará, através da PARATUR. O primeiro deles foi o de $n^{\circ}$. 2002CV0040, celebrado em julho de 2002. Entre seus objetivos constava o que tratava da finalização da elaboração das Estratégias de Ecoturismo do polo Belém/Costa Atlântica, objeto deste estudo. Há que se destacar que mesmo a vigência do convênio tendo sido prorrogada por duas vezes, ele não foi executado totalmente. Em parecer de 15 de dezembro de 2003, o MMA optou pelo cancelamento do referido convênio e requereu a devida prestação de contas ao NGP/PROECOTUR-PA; e no Parecer Técnico $n^{\circ} .25$ datado de 26 abril de 2006, o MMA aprovou a prestação de contas apresenta pelo NGP/PROECOTUR-PA.

Há que se relatar que o NGP/PROECOTUR-PA passou por seis alterações em sua coordenação, quatro das quais somente nos dois primeiros anos da implementação do Programa. Outro ponto importante a ser destacado é que tanto a UGP quanto o NPG/PROECOTUR-PA não estavam suficientemente preparados para lidar com as minúcias administrativas, com as normas de um contrato internacional, mais ainda junto ao BID e da maneira como foi feito o acordo. Agravante quanto à 
gestão administrativa foi a mudança na estrutura institucional tanto em nível estadual, de um órgão a outro; quanto no federal, dentro de um mesmo órgão administrativo. Isso contribuiu para gerar uma desaceleração no processo de implementação do Programa, uma vez que para cada modificação foi necessário um tempo de acomodação, ou seja, de adequação a nova estrutura.

\section{O PROECOTUR no Polo Belém/Costa Atlântica: a implementação e a participação dos atores sociais}

A implementação do PROECOTUR no polo Belém/Costa Atlântica teve início em 2001, com o processo licitatório para a contratação da empresa de consultoria responsável por elaborar o estudo do potencial ecoturístico e as estratégias para o desenvolvimento do ecoturismo no referido polo. O Termo de Referência (TR) para tal licitação apresentava: a delimitação da área objeto do estudo ${ }^{8}$, o objetivo da licitação, que era a elaboração do "Diagnóstico do Potencial Ecoturístico do polo Belém/Costa Atlântica" e das "Estratégias para o Desenvolvimento do Ecoturismo" no referido polo; as atividades a serem desenvolvidas pela empresa contratada; os produtos que deveriam ser entregues ${ }^{9}$, o modo de apresentação desses produtos; prazo de execução ${ }^{10}$, e um cronograma para a realização das atividades que a empresa deveria cumprir.

Venceu tal processo o Instituto Brasileiro de Administração para o Desenvolvimento (IBRAD), único a atender aos requisitos do edital e cuja Proposta Técnica apresentada foi avaliada e aprovada pelo NGP/PROECOTUR-PA. E após a assinatura do contrato, o IBRAD formulou seu Plano de Trabalho (PARÁ, 2001) que foi aprovado pela coordenação paraense do PROECOTUR em 03 de dezembro de 2001, em reunião com a presença, também, de representantes do MMA, PARATUR e do próprio IBRAD. Nessa reunião, por sugestão da coordenação estadual do programa, a área de abrangência do polo foi dividida em dois grupos. O grupo 1 ficou formado por Belém, Curuçá, Maracanã, Marapanim, Salinópolis e São João de Pirabas; e o grupo 2, por Bragança, Tracuateua, Augusto Corrêa e Viseu. Após isso, o IBRAD iniciou efetivamente as suas atividades.

Inicialmente, realizaram-se duas oficinas de planejamento estratégico, em janeiro de 2002, uma no município de Salinópolis e outra no município de Tracuateua. Com base nas informações oriundas de tais oficinas, o IBRAD realizou em fevereiro de 2002 pesquisa de campo em todos os municípios do polo. Dois dos objetivos dessa pesquisa consistiam em comprovar a potencialidade ecoturística dos atrativos apontados pelos representantes dos municípios durante as oficinas e identificar as necessidades de infraestrutura para o desenvolvimento dos roteiros e, consequentemente, do ecoturismo no Belém/Costa Atlântica. Tal pesquisa foi realizada por via terrestre e marítima e foi acompanhada por representantes dos municípios, do NGP/PROECOTUR-PA, da PARATUR e da SECTAM.

Um seminário para a apresentação dos resultados gerados durante a pesquisa foi realizado no município de Bragança, no dia 12 de março de 2002. Nele o IBRAD apresentou o "Diagnóstico do Potencial Ecoturístico" do polo e a versão preliminar das "Estratégias de Desenvolvimento do 
Ecoturismo". Isso conforme ditava o TR. Em seguida, o NGP/PROECOTURPA interveniou o encaminhamento desses documentos aos municípios, para as respectivas considerações e sugestões. Após isso, o IBRAD procedeu às correções e os encaminhou às coordenações estadual e federal do Programa.

Vale ressaltar que isso tudo aconteceu simultaneamente às mudanças ocorridas na coordenação do PROECOTUR no Pará, descritas na seção anterior, porém as ações do Programa continuaram a ser desenvolvidas. Como o contrato do Programa previa a realização de cursos e oficinas de capacitação, nos dias 06 e 07 de novembro de 2003 foi realizada, no município de Augusto Corrêa, a oficina de sensibilização do polo Belém/Costa Atlântica, tendo como público alvo os gestores de turismo, a iniciativa privada a sociedade civil organizada. Ocorreram, também, três cursos de capacitação, no ano de 2005: Qualidade no Atendimento aos Visitantes; Condução de Visitantes; e Planejamento e Gestão de Empreendimentos Ecoturísticos. Observa-se que, no âmbito do PROECOTUR, foram poucas as ações desenvolvidas no polo Belém/Costa Atlântica.

No que diz respeito à participação dos atores sociais envolvidos com o PROECOTUR, em conformidade com o contrato firmado com o BID, para que isso acontecesse foi definida a criação de instâncias de governança em nível federal, estadual e municipal. Nesse sentido, a UGP e os NGP em cada Estado, seriam responsáveis, respectivamente, pela execução e coexecução do Programa. O GTC-Amazônia e os GTC-Estaduais, de caráter consultivo, auxiliariam a UGP e os NGP. E, em cada município dos polos, seriam criados os GTO, considerados braços operacionais do PROECOTUR, sendo que representantes de cada GTO tomariam parte do GTC-Estadual. Em relação aos GTC e GTO, a orientação era para fossem tripartites. No Pará, apenas os GTO do Tapajós foram criados e chegaram a funcionar efetivamente.

Em que pesem os GTO do polo Belém/Costa Atlântica não tenham sido criados, os atores sociais envolvidos participaram do processo de implementação do programa. A participação deles aconteceu efetivamente em dois momentos: nas oficinas de planejamento estratégico sucedidas em Salinópolis e Tracuateua; e no seminário de apresentação da versão preliminar das "Estratégias", ocorrido em Bragança. A mobilização dos atores foi realizada pelo NGP/PROECOTUR-PA que contatava o órgão oficial de turismo ou meio ambiente, de acordo com cada município, e o incumbia de articular a participação da iniciativa privada, da sociedade civil organizada e das demais instituições públicas interessadas.

Nas oficinas de planejamento, a participação dos atores se deu a partir de grupos de trabalho formados pelos representantes dos municípios. O objetivo desses grupos era discutir as potencialidades e necessidades de cada município; propor circuitos ecoturísticos integrados; e elaborar a agenda da pesquisa de campo a ser realizada pela consultoria IBRAD. No seminário realizado em Bragança, a participação também se deu através de grupos de trabalho cujos integrantes analisaram os resultados da pesquisa in loco apresentados pelos consultores, bem como os roteiros propostos, tecendo suas considerações e sugestões para melhorá-los. 
A participação dos atores sociais durante as oficinas e o seminário, a partir do disposto por Bordenave (2002), enquadra-se no grau de "elaboração/recomendação" da escala por ele defendida. Todavia, posto que para ele o principal no processo participativo seja a tomada de decisão, ela equivale ao nível 3 - elaboração de planos, programas e projetos. Pode-se dizer, então, que é um status moderado de participação. A se considerar a visão de Souza, M. (2006a, 2006b), que relaciona participação com autonomia, tem-se a participação dos atores enquadrada na categoria 6 parceria, em que há uma autonomia individual e coletiva moderada.

\section{A herança do PROECOTUR}

É possível dizer que em que pese o PROECOTUR não tenha proporcionado aportes econômicos ao polo Belém/Costa Atlântica, ele o fez de outros modos. Em termos de desenvolvimento sustentável os benefícios foram nulos, uma vez que inexistiram investimentos em infraestrutura ou qualquer outro tipo de obras. Todavia, suscitou contribuições mais importantes. Uma delas foi a gênese de uma maneira nova de pensar 0 desenvolvimento, conciliando a utilização dos recursos e a preservação ambiental. Outra se refere à necessidade de união entre os segmentos da sociedade e entre os municípios do Belém/Costa Atlântica em defesa do bem comum.

Nesse contexto, convém resgatar o pensar de Souza, M. (2006a, $2006 \mathrm{~b})$ de que desenvolvimento incide em uma mudança social positiva. $E$ que para obtê-lo é imprescindível atentar para os anseios e necessidades dos atores sociais, estes imbuídos de suas particularidades culturais, históricas e geográficas; bem como para as relações sociais e para o espaço no qual elas ocorrem. Dessa feita, como o desenvolvimento socioespacial se constitui em um processo, um devir que implica em uma "[...] melhoria da qualidade de vida e um aumento da justiça social' (SOUZA, M., 2006a, p. 61), observa-se que o PROECOTUR apenas o estimulou; e no que tange ao desenvolvimento sustentável, partindo-se do que preconiza o conceito da CMMAD, este também foi apenas principiado. Em suma, não se teve ou tem tal desenvolvimento no polo, mas sim foi iniciado o processo para alcançá-lo.

Chegou-se a tais constatações ao se comparar os dados dispostos nas Tabelas 3 e 4, referentes ao ano de 2008, com os descritos na seção três deste artigo e com as informações obtidas nas entrevistas realizadas com os atores sociais do polo. Isto, pois, eles esperavam, em 2001, que o PROECOTUR contribuísse para melhorar a situação socioeconômica do polo. Todavia, não foi isso exatamente o que aconteceu.

A expectativa dos atores sociais era que os recursos advindos do PROECOTUR viabilizassem o incremento do ecoturismo no polo, como alternativa para o desenvolvimento sustentável e socioespacial local, em contraposição as atividades econômicas até então ali realizadas. Com isso haveria um aumento no fluxo de (eco)turistas para o polo desencadeando o efeito multiplicador do turismo, o que repercutiria na implantação de novos equipamentos (eco)turísticos e em um sem fim de atividades direta e indiretamente ligadas ao turismo. Isto contribuiria para a geração de emprego e renda e, por conseguinte, para a melhoria na qualidade de vida 
da população. Entretanto, não houve aporte financeiro do Programa ao polo, pois não foram feitos investimentos em infraestrutura ou qualquer outro tipo de obras.

Tabela 3: Área, população (total e por situação da unidade domiciliar), densidade, urbanização do polo Belém/Costa Atlântica - 2008.

Table 3: Area (total and situation of the household) population density, urbanization of the Belém/Atlantic Coast pole - 2008 .

\begin{tabular}{|c|c|c|c|c|c|c|}
\hline & \multirow{2}{*}{ Área $\left(\mathrm{km}^{2}\right)$} & \multicolumn{3}{|c|}{ População (hab.) } & \multirow{2}{*}{$\begin{array}{l}\text { Densidade } \\
\left(\mathrm{hab} . \mathrm{km}^{2}\right)\end{array}$} & \multirow{2}{*}{$\begin{array}{c}\text { Taxa de } \\
\text { Urbanização } \\
(\%)\end{array}$} \\
\hline & & Total & Urbana & Rural & & \\
\hline $\begin{array}{l}\text { Polo } \\
\text { Belém/Costa } \\
\text { Atlântica }\end{array}$ & 13167,601 & 1813559 & 1624587 & 188972 & 137,72 & 89,58 \\
\hline
\end{tabular}

Fonte: Brasil (2007).

Source: Brasil (2007).

Tabela 4: Rendimento médio mensal, rendimento médio da população ocupada (todos os trabalhos), Produto Interno Bruto (PIB) a preço de mercado corrente, PIB Per Capita a preço de mercado corrente e Estrutura produtiva do polo Belém/Costa Atlântica - 2005.

Table 4: Average monthly income, average income of the employed population (all jobs), Gross Domestic Product (GDP) at current market prices, GDP Per Capita at current market prices and productive structure of the Belém/Atlantic Coast pole - 2005 .

\begin{tabular}{|c|c|c|c|c|c|c|c|}
\hline & \multirow{2}{*}{$\begin{array}{c}\text { Rendimento } \\
\text { Médio } \\
\text { Mensal }(\mathrm{R} \$ \\
1,00) \\
\text { Total }\end{array}$} & \multirow{2}{*}{$\begin{array}{c}\begin{array}{c}\text { Rendimento } \\
\text { Médio }\end{array} \\
\text { Total }\end{array}$} & \multirow{2}{*}{$\begin{array}{c}\text { PIB } \\
\text { (R\$ mil) }\end{array}$} & \multirow{2}{*}{$\begin{array}{c}\text { PIB Per } \\
\text { Capita } \\
\text { (Valores } \\
\text { Constantes } \\
\text { R\$) }\end{array}$} & \multicolumn{3}{|c|}{ Estrutura Produtiva } \\
\hline & & & & & $\begin{array}{c}\text { Agropec. } \\
(\%)\end{array}$ & $\begin{array}{l}\text { Ind. } \\
(\%)\end{array}$ & $\begin{array}{c}\text { Serv. } \\
(\%)\end{array}$ \\
\hline $\begin{array}{c}\text { Polo } \\
\text { Belém/ } \\
\text { Costa } \\
\text { Atlântica }\end{array}$ & NE & NE & 12045951 & 6816 & 18,17 & 11,62 & 70,12 \\
\hline
\end{tabular}

Fonte: Elaborado por Vânia L. Q. Nascimento (2008) a partir de Pará (2007).

Source: Prepared by Vânia L. Q. Nascimento (2008) from Pará (2007).

É bem verdade que nos dois momentos, 2001 e 2008, o polo apresentava taxa de urbanização elevada, mas esses números refletiam a realidade apenas dos municípios de Belém, Bragança, Salinópolis e São João de Pirabas nos quais a população residente na zona urbana era maior que na rural. Nos outros municípios acontecia justamente o contrário. A população desses municípios residente na zona rural carecia de abastecimento de água, energia elétrica e condições básicas de saneamento, privilégios dos moradores da zona urbana.

Todavia, algumas mudanças nas condições de vida da população do polo puderam ser observadas. Bem ou mal programas como 0 de Erradicação do Trabalho Infantil (PETI), o Agente Jovem, o Bolsa Escola, o Programa Saúde da Família (PSF) e o de Agentes Comunitário de Saúde (ACS) colaboraram para que as famílias atendidas adquirissem uma renda adicional, o que Ihes permitia uma qualidade melhor de vida. Isso continua 
ocorrendo ultimamente com o Bolsa Família. É bem verdade que os critérios para a seleção dos beneficiários desse auxílio têm sido discutidos e muitas são as denúncias de fraudes. Mas, é inquestionável que na maioria dos casos tal programa é a fonte única de renda de muitas famílias.

O programa federal Luz para Todos também tem contribuído para melhorar a qualidade de vida no polo. Através dele, no início dos anos 2000, as comunidades da zona rural começaram a receber posteamento e instalação de rede elétrica. Atualmente, a quase totalidade das comunidades rurais dos municípios do polo já está eletrificada. É possível dizer então que - Belém/Costa Atlântica alcançou certo nível de desenvolvimento socioespacial gerado não a partir ou por conta do PROECOTUR, mas sim pelas contribuições dos programas supracitados.

Em relação aos aspectos turísticos, considerando o panorama existente em 2001 descrito na seção três, em 2008 a situação do Belém/Costa Atlântica estava um tanto quanto diferente. Atrativos turísticos novos foram identificados e a quantidade dos equipamentos e serviços turísticos foi ampliada. Quanto à gestão da atividade, esta também passou por modificações incluindo a criação de novas instâncias de governança.

Convém explicar que, com a metodologia nova de inventariar a oferta turística definida pelo MTUR, através da Secretaria Nacional de Políticas de Turismo (SNPTUR) (BRASIL, 2006), a caracterização turística do polo foi revista. Com isso, o mesmo continuou a apresentar atrativos turísticos em todas as categorias, agora classificados como: natural; cultural; atividades econômicas; eventos permanentes; e realizações técnicas e científicas contemporâneas. Quanto ao patrimônio natural, ademais das unidades de conservação existentes no polo em 2001, foram instituídas mais seis, enquadradas na categoria reserva extrativista (RESEX) marinha. Foram elas: a Mãe Grande de Curuçá, em Curuçá; as de Maracanã e Tracuateua, respectivamente, nos municípios de mesmo nome; a Irai-Peroba, em Augusto Corrêa; a Caeté-Taperaçu, em Bragança; e a Gurupi-Piriá, em Viseu.

Os equipamentos e serviços turísticos também foram alterados. Em 2008, o polo Belém/Costa passou a contar com 272 meios de hospedagem, perfazendo um total de 5664 unidades habitacionais e 12528 leitos; 241 estabelecimentos de alimentos e bebidas; 93 agências de viagens e turismo e transportadoras turísticas; 68 espaços para eventos; 164 locais para lazer e entretenimento; e 08 outros serviços turísticos. Houve uma melhora quantitativa expressiva, conforme pode ser observado no Quadro 1. Entretanto em termos qualitativos, mormente quanto à prestação dos serviços, tal melhora não pode se comprovada incontestavelmente.

Em se tratando da gestão do turismo no polo, todos os municípios do Belém/Costa Atlântica possuem como órgão gestor de turismo uma secretaria municipal legalmente constituída e com dotação orçamentária, mesmo que mínima. Augusto Corrêa é o único município que não tem secretaria, sendo apenas um departamento. Bragança, Salinópolis e Tracuateua foram municípios que realizaram concurso público para provimento de cargos na área de turismo. Entretanto, há ainda aqueles que mesmo possuindo secretaria municipal de turismo, o que constituiu uma 
evolução grande, não possuem técnicos da área em seus quadros de pessoal.

Quadro 1: Equipamentos e serviços turísticos existentes no polo Belém/Costa Atlântica em 2001 e 2008.

Table 1: Equipment and tourism services existing in Belém/Atlantic Coast pole in 2001 and 2008.

\begin{tabular}{|c|c|c|c|c|c|c|c|c|}
\hline \multirow[b]{2}{*}{ ANO } & \multicolumn{3}{|c|}{ Meios de Hospedagem } & \multirow[b]{2}{*}{$\begin{array}{c}\text { Alimentos e } \\
\text { bebidas }\end{array}$} & \multirow{2}{*}{$\begin{array}{c}\text { Agência de } \\
\text { viagens e } \\
\text { transporte } \\
\text { turístico }\end{array}$} & \multirow{2}{*}{$\begin{array}{l}\text { Espaço } \\
\text { para } \\
\text { eventos }\end{array}$} & \multirow{2}{*}{$\begin{array}{c}\text { Locais } \\
\text { para } \\
\text { Entrete- } \\
\text { nimento e } \\
\text { lazer }\end{array}$} & \multirow{2}{*}{$\begin{array}{c}\text { Outros } \\
\text { serviços } \\
\text { turísticos }\end{array}$} \\
\hline & Quant. & UH & Leitos & & & & & \\
\hline $2001^{*}$ & 159 & 3699 & 7474 & 185 & 41 & 10 & 28 & 01 \\
\hline $2008^{* *}$ & 272 & 5664 & 12528 & 241 & 93 & 68 & 164 & 08 \\
\hline
\end{tabular}

Fonte*: Elaborado por Vânia Nascimento (2008) a partir de Companhia Paraense de Turismo (2004).

Fonte $^{\star \star}$ : Elaborado por Vânia Nascimento (2008) a partir de Associação Brasileira das Agências das Agências de Viagens/Seção Pará (2008); Belém Convention \& Visitors Bureau (2008); Companhia Paraense de Turismo (2007).

Source*: Prepared by Vânia Nascimento (2008) from Pará Tourism Company (2004).

Source ${ }^{\star \star}$ : Prepared by Vânia Nascimento (2008) from the Brazilian Association of Travel Agencies/Section Pará (2008); Belém Convention \& Visitors Bureau (2008);

Pará Tourism Company (2007).

Há que se ressaltar que simultaneamente à implementação do PROECOTUR no polo Belém/Costa Atlântica foram realizadas ações de outros dois programas, os quais como que absorveram alguns atributos do PROECOTUR. Tais programas foram o PRT - Roteiros do Brasil, do governo federal, e o Programa SEBRAE de Turismo Amazônia Atlântica Paraense, do Centro de Resultados da Unidade de Negócios de Capanema. O PRT prima, a exemplo do PROECOTUR, pelo desenvolvimento do turismo pautado na região turística, denominada no Pará de polo. Enquanto que, entre suas ações, o Programa SEBRAE previa a criação dos consórcios gestores de turismo em cada município, similarmente aos GTO do PROECOTUR.

Ainda sobre tais programas é pertinente tecer algumas considerações. Os dois congregam um componente de planejamento; um de capacitação, por meio da realização de cursos de capacitação de mão de obra; um de gestão participativa compartilhada, com a criação dos consórcios gestores de turismo e o fórum de turismo do polo; bem como a criação de circuitos/rotas integradas de negócios turísticos. Ambos objetivam a promoção do desenvolvimento sustentável do polo e, por conseguinte, condições de vida melhores para a população local. A diferença entre o PRT e o Programa SEBRAE é que este último foi planejado especificamente para o polo, enquanto que o primeiro o foi para todos os estados e regiões turísticas brasileiras. E o PROECOTUR foi pensado especificamente para a Amazônia e deveria considerar a especificidade de polo onde seria implementado.

Por fim, é imprescindível enfatizar que o PROECOTUR passou por descontinuidade em seu processo de implementação. Isso ora por conta das mudanças nas coordenações, ora em virtude da própria dinâmica de 
realização das ações. Todavia, em 2008, quando se fez a pesquisa, ele estava na finalização da primeira fase, a de pré-investimento, como previa o contrato do empréstimo.

De acordo com representantes da coordenação nacional do Programa na época da pesquisa (informação verbal) ${ }^{11}$, os produtos dessa primeira fase do PROECOTUR, e que estavam na conclusão, eram três documentos escritos. O primeiro era o estudo da oferta turística da Amazônia Legal, destacando o perfil da oferta turística e dos serviços bem como as dificuldades e potencialidades da região. O segundo, o estudo de mercado, apontando as características dos mercados nacional e internacional consumidores do produto ecoturístico amazônida. E o terceiro eram as estratégias para o desenvolvimento do ecoturismo na região Amazônica, fruto da análise das informações dos estudos da oferta e de mercado.

Ao final do ano de 2008, concluiu-se a elaboração desses documentos e teve início a apresentação das estratégias a cada um dos estados contemplados no PROECOTUR, para análise. A versão preliminar da "Estratégia para o Desenvolvimento do Turismo Sustentável na Amazônia Brasileira"12, foi apresentada ao Pará em oficina realizada no dia 05 de dezembro, durante a IV Feira Internacional de Turismo da Amazônia $(\text { FITA })^{13}$. A análise desse documento por parte dos estados perdurou por mais algum tempo, após o qual a coordenação nacional do Programa procedeu aos ajustes necessários. E, em palestra realizada em 12 de agosto de 2010 durante a V FITA, a gerente técnica do Programa nessa data fez a apresentação da versão final do referido documento, que é composto, ademais das próprias estratégias, pelos estudos da oferta turística da Amazônia Legal e dos mercados consumidores nacional e internacional.

Esses documentos constituem a herança do PROECOTUR legada ao MTUR. Isto, pois, a segunda fase do Programa, em conformidade com o disposto no Plano Nacional do Turismo 2007-2010: uma viagem de inclusão, "[...] denominada PRODETUR Norte, será de responsabilidade do Ministério do Turismo" (BRASIL, 2007, p.69). Nesse sentido, a então coordenação do PROECOTUR no MMA postulava que esses documentos fossem tomados pelo MTUR, mormente a "Estratégia", como "[...] referência de um conjunto de princípios, de estratégias, de projetos, de ações e de investimentos", segundo palavras da gerente técnica do Programa durante a palestra. Isto, pois, é preciso ter, quanto à região Amazônica, "[...] um olhar diferenciado que ela merece pelas características que ainda possui. Por isso, o modelo de desenvolvimento para a Amazônia não pode ser o mesmo das outras regiões, outros biomas do país", ressaltava a gerente técnica do PROECOTUR.

\section{Notas conclusivas}

Foram várias as constatações a que se chegou com este estudo. De início tem-se que o PROECOTUR apresentou três grandes diferenciais: foi concebido e formulado especificamente para a Amazônia; enfocou um único segmento do turismo, o ecoturismo; e foi pautado na sustentabilidade. Esse 
último possibilitou a transversalização da questão ambiental no âmbito de uma política setorial.

Constatou-se, também, que o processo de descontinuidade passado pelo Programa ocorreu por fatores variados. Alguns deles de ordem administrativa, referentes à capacitação técnica insuficiente na esfera das administrações públicas, notadamente as estaduais, para conduzir a sua implementação, principalmente quanto à gestão administrativo-financeira dos recursos. Outros de ordem política, mormente relacionados ao tempo político, ou seja, as mudanças de governo em âmbito federal e estadual, ocorridas a cada dois anos. Houve ainda os econômicos, uma vez que os valores liberados e utilizados através dos convênios firmados entre MMA e o estado do Pará ficaram aquém do proposto. $O$ que contribuiu para que a esfera federal da administração pública do Programa cancelasse recursos.

No que diz respeito à participação dos atores sociais, esta não se deu como originalmente previsto, pois os GTO do polo Belém/Costa Atlântica não foram criados. Todavia, a Consultoria IBRAD possibilitou que isso acontecesse através da dinâmica que adotou para a realização de suas ações no polo, por meio das oficinas e do seminário nos quais eles puderam participar. Contudo, tais atores ainda necessitam ter, a se considerar o posto por Souza, M. (2006a, 2006b), autonomia e poder de decisão maiores. E, mais, ter ciência disto e lutar por sua inserção nos processos decisórios.

Averiguou-se, ainda, que o turismo no polo Belém/Costa Atlântica encontra-se pouco estruturado. Isto em virtude da descontinuidade do Programa, gerada pelo atraso na finalização da primeira fase, que resultou na não consolidação do ecoturismo como promotor de desenvolvimento, segundos os conceitos propostos pelo CMMAD (1987 apud BUARQUE, 2001), Simonian (2007a) e Souza, M. (2006a, 2006b), quer sustentável quer socioespacial, para o polo. Porém, foi dado início a tal desenvolvimento com o processo para a elaboração das estratégias de ecoturismo para a área em questão.

Em relação aos preceitos da análise de políticas públicas, defendidos por Frey (2000) e Souza, C. (2006), conclui-se que a implementação do Programa não foi monitorada ou avaliada em tempo algum, quer pela UGP quer pelo NGP/PROECOTUR-PA. O que contribuiu muito para que os fatores que inviabilizaram a continuidade do PROECOTUR não fossem identificados em tempo hábil e pudessem ser contornados, de modo que a implementação do Programa ocorresse como previsto. Todavia, essa fragilidade foi revisada na "Estratégia para o desenvolvimento do turismo sustentável na Amazônia Legal", que instituiu como uma de suas diretrizes a "Informação e Monitoramento da Estratégia". Nele, contemplou-se, ainda, a participação dos atores, na diretriz "Políticas Públicas e Fortalecimento Institucional" e mediante o envolvimento deles nos fóruns e conselhos municipais.

É válido destacar algumas falhas importantes na implementação do PROECOTUR no polo Belém/Costa Atlântica. A primeira é que o Programa possuía um arranjo de execução complexo, porém inexistia alguém com a incumbência de intermediar a inter-relação, a interlocução entre os partícipes desse arranjo. Isto obstava a difusão de informações, a implementação do 
Programa e a mobilização de todos os atores envolvidos. A segunda foi a não criação dos GTO dos municípios, o que fez com que a participação dos atores sociais do polo ocorresse apenas por ocasião das oficinas e seminários.

A terceira falha foi em relação à qualificação dos atores sociais, notadamente dos gestores do NGP/PROECOTUR-PA e dos municípios envolvidos, que embora contemplada no componente "Capacitação" do contrato com o BID ocorreu somente durante as fases de concepção e formulação do Programa. A quarta consistiu na não divulgação ou socialização das informações. Isto, pois, posteriormente as oficinas e ao seminário no polo Belém/Costa Atlântica, os atores sociais partícipes do processo não tomaram mais conhecimento do andamento do Programa.

É imprescindível apontar algumas sugestões. Inicialmente, a Amazônia Legal carece ser pensada com acuidade, em virtudes de suas peculiaridades. E os planos, programas e projetos para ela elaborados devem ser acompanhados por todos os atores sociais, principalmente as comunidades locais, desde a formulação até a implementação. Isto implica na instituição ou revitalização das instâncias de governança, essencialmente tripartites, independentemente da modalidade adotada (conselhos, consórcios ou fóruns de turismo).

A tratar-se especificamente do polo estudado, embora não seja prioritário no âmbito do PRT, o governo estadual necessita lhe destinar atenção, mesmo que ínfima, visando atender às demandas local e regional existentes. Caso isso não aconteça, a potencialidade turística, a facilidade de acesso, a infraestrutura básica e os equipamentos e serviços turísticos não conseguirão manter o fluxo turístico já existente ou mesmo elevá-lo. Assim, é imperativo que os atores sociais do polo se unam e lutem junto aos gestores públicos em prol da atividade turística como ferramenta promotora de desenvolvimento sustentável e socioespacial efetivos.

\section{Referências bibliográficas}

BENI, M.C. Política e planejamento de turismo no Brasil. São Paulo: Aleph, 2006. (Série Turismo).

BID. Contrato de empréstimo $n \circ$. 1216/OC-BR. 32 p. Washington, D.C., ago. 2000. (mimeografado).

BORDENAVE, J.E.D. O que é participação. 8. ed. 3. reimp. São Paulo: Brasiliense, 2002. (Coleção Primeiros Passos).

BRASIL. Empresa Brasileira de Turismo. Diretrizes para uma Política Nacional de Ecoturismo. Brasília, 1994.

BRASIL. Instituto Brasileiro de Geografia e Estatística. Censo Demográfico 2000. Brasília, DF, 2000. Disponível em: $<$ http://www.ibge.gov.br/home/estatistica/populacao/censo2000/default.shtm >. Acesso em: 21 ago. 2008.

BRASIL. Ministério do Meio Ambiente. Estratégias para o desenvolvimento integrado do ecoturismo na Amazônia Legal. [S. I.], 1997. 
BRASIL. Ministério do Turismo. Ecoturismo: visitar para conservar e desenvolver a Amazônia. Brasília: MMA/SCA/PROECOTUR, 2002.

BRASIL. Ministério do Turismo. Manual do Pesquisador - Inventário da Oferta Turística: instrumento de pesquisa. Brasília, dez. 2006.

BRASIL. Ministério do Turismo. Plano Nacional de Turismo (PNT) 20072010 - uma viagem de inclusão. Brasília, 2007.

BRASIL. Ministério do Turismo. Programa de regionalização do turismo roteiros do Brasil: diretrizes operacionais. Brasília, 2004.

BUARQUE, S.C. Construindo o desenvolvimento local sustentável: metodologia de planejamento. 3. ed. Rio de Janeiro: Garamond, 2006.

BUARQUE, S.C. Desenvolvimento sustentável: em busca de uma teoria da complexidade do desenvolvimento. Revista de Ciências da Administração, Recife, ano I, v. 1, p. 67-79, 2001. Disponível em: $<$ http://www.educacao.adm.br/pdf/2001/sergio buarque.pdf>. Acesso em: 27 abr. 2007.

CAMPOS, R.I.R. Sustentabilidade, turismo e gestão do patrimônio arqueológico: limites e possibilidades no Maracá (AP) e Serra dos Martírios/Andorinhas (PA). 2008. 350 f. Tese (Doutorado em Desenvolvimento Sustentável do Trópico Úmido)-Núcleo de Altos Estudos Amazônicos, Universidade Federal do Pará, Belém, 2008.

CASTRO, E. Estado e políticas públicas na Amazônia em face da globalização e da integração de mercados. In: COELHO, M.C.Nunes et al. (Org.) Estado e políticas públicas na Amazônia: gestão do desenvolvimento regional. Belém: CEJUP, NAEA/UFPA, 2001. p. 7-32.

CHIZZOTTI, A. Pesquisa em ciências humanas e sociais. São Paulo: Cortês, 1991.

COSTA, F.A. As ciências, o uso dos recursos naturais na Amazônia e a noção de desenvolvimento sustentável: por uma interdisciplinaridade ampla. In: VIEIRA, I.C.G. et al. Diversidade biológica e cultural da Amazônia. Belém: Museu Paraense Emílio Goeldi, 2001a. p. 299-318.

COSTA, F.A. Desenvolvimento sustentável na Amazônia: o papel estratégico do campesinato. In: VIANA, G.; SILVA, M.; DINIZ, N. (Org.). O desafio da sustentabilidade: um debate socioambiental no Brasil. São Paulo: Perseu Abramo, 2001b. p. 289-313. (Coleção pensamento petista).

CRUZ, R.C. Política de turismo e território. 3 ed. São Paulo: Contexto, 2002. (Coleção Turismo).

DEMO, P. Participação é conquista: noções de política social participativa. São Paulo: Cortez, 1988.

DENCKER, A.F.M. Métodos e técnicas de pesquisa em turismo. 5. ed. São Paulo: Futura, 2001.

DIAS, R. Planejamento do turismo: política e desenvolvimento do turismo no Brasil. São Paulo: Atlas, 2003.

FARIA, C.A.P. A política de avaliação das políticas públicas. Revista Brasileira de Ciências Sociais, v. 20, n. 59, p. 97-109, out. 2005. 
FIGUEIREDO, Argelina Cheibub. Princípios de justiça e avaliação de políticas. Lua Nova Revista de Cultura e Política, [s.I.], n. 39, p. 73-103, 1997.

FIGUEIREDO, S.L. Ecoturismo e Desenvolvimento Sustentável: alternativa para o desenvolvimento da Amazônia? In: FIGUEIREDO, S.L. (Org.). 0 ecoturismo e a questão ambiental na Amazônia. Belém: UFPA/NAEA, 1999a, p. 75-126.

FIGUEIREDO, S.L. Ecoturismo, festas e rituais na Amazônia. Belém: NAEA/UFPA, 1999b.

FREY, K. Políticas públicas: um debate conceitual e reflexões referentes à prática da análise de políticas públicas no Brasil. Planejamento e Políticas Públicas, [s.l.], n. 21, p. 211-259, jun. 2000.

GRASSO, P.G. What makes an evaluation useful? Reflections from experience in large organizations. American Journal of Evaluation, v. 24, n. 4, p. 507-514, 2003. Disponível em: <http://aje.sagepub.com>. Acesso em: 22 ago. 2007.

HALL, P.A.; TAYLOR, R.C.R. As três versões do neo-institucionalismo. Lua Nova, [s. I.], n. 58, p. 193-223, 2003.

LEVITON, L.C. Evaluation Use: advances, challenges and applications. American Journal of Evaluation, v. 24, n. 4, p. 525-535, 2003. Disponível em: <http://aje.sagepub.com>. Acesso em: 22 ago. 2007.

MATUS, C. Adeus senhor presidente. Recife: Litteris Editora, 1989.

NASCIMENTO, V.L.Q. Ecoturismo, lendas e mitos: realidade e possibilidades na capital paraense. Belém, 2002. $75 \mathrm{f}$. Trabalho de Conclusão de Curso (Especialização em Planejamento e Gestão de Turismo) - Centro de Ensino Superior do Pará, 2002.

NEVES, J.L. Pesquisa qualitativa - características, usos e possibilidades. Caderno de Pesquisa em Administração, São Paulo, v. 1, n. 3, p. 1-5, 2. sem. 1996.

NÓBREGA, W. Turismo: planejamento e políticas públicas na Amazônia. Rio de Janeiro: E-papers, 2007.

OLIVEIRA, A.P. Turismo e desenvolvimento: planejamento e organização. 5 ed. rev. e ampl. São Paulo: Atlas, 2005.

OLIVEIRA, R.C. O trabalho do antropólogo: olhar, ouvir, escrever. Revista de Antropologia, São Paulo, USP, v. 39, n. 1, p. 13-37, 1996.

PARÁ. Companhia Paraense De Turismo. Diagnóstico do potencial ecoturístico do polo Belém/Costa Atlântica - versão preliminar. Belém, 2004. (Consultoria realizada pelo Instituto Brasileiro de Administração para o Desenvolvimento - IBRAD).

PARÁ. Secretaria Executiva de Ciência, Tecnologia e Meio Ambiente. Plano de Trabalho do Instituto Brasileiro de Administração para 0 Desenvolvimento. 14 p. Belém, 2001. (mimeografado). 
PARÁ. Secretaria Executiva de Ciência, Tecnologia e Meio Ambiente. Proposta do Governo do estado do Pará visando a cooperação técnica para o desenvolvimento do turismo sustentável junto ao Banco Interamericano de Desenvolvimento - BID. 11 p. Belém, jul. 1999. (mimeografado).

PARÁ. Secretaria Executiva de Estado de Planejamento, Orçamento e Finanças. Produto Interno Bruto dos Municípios do Pará 2005. Belém, 2007c. Disponível em: $<$ http://www.sepof.pa.gov.br/pdf/PIB Municipal 2005.pdf>. Acesso em: 21 ago. 2008.

PETROCCHI, M. Gestão de polos turísticos. São Paulo: Futura, 2001.

PINTO, P.M. Unidades de conservação, turismo e exclusão social no Parque Estadual Serra dos Martírios/Andorinhas. Belém, 2006. 150 f. Dissertação (Mestrado em Serviço Social) - Universidade Federal do Pará, 2006.

QUARESMA, H.D.A. O desencanto da princesa: pescadores tradicionais e turismo na área de proteção ambiental de Algodoal/Maiandeua. Belém: NAEA, 2003.

RUEDIGER, M.A.; RICCIO, V. O novo contrato social: desenvolvimento e justiça em uma sociedade complexa. In: CAVALCANTI, B.S.; RUEDIGER, M.A.; SOBREIRA, R. (Org.). Desenvolvimento e construção nacional: políticas públicas. Rio de Janeiro: Editora FGV, 2005. p. 17-31.

SACHS, I. Estratégias de transição para o século XXI. In: BURSZTYN, M. (Org.). Para pensar o desenvolvimento sustentável. São Paulo: Editora Brasiliense, 1993. p. 29-56.

SILVA, M.O.S. Avaliação de políticas e programas sociais: aspectos conceituais e metodológicos. In: SILVA, M.O.S. et al. (Org.). Avaliação de políticas e programas sociais: teoria \& prática. São Paulo: Veras editora, 2001. p. 37- 93.

SILVA, M. et al. A transformação do espaço amazônico e seus reflexos na condição atual da cobertura e uso da terra. Novos Cadernos NAEA, Belém, v. 16, n. 1, p. 229-248, jun. 2013.

SIMONIAN, L.T.L. Tendências recentes quanto à sustentabilidade no uso dos recursos naturais pelas populações tradicionais amazônidas. In: ARAGÓN, E. (Org.). Populações e meio ambiente na pan-Amazônia. Belém: Editora do NAEA/UFPA, 2007a. p. 25-44.

SIMONIAN, L.T.L. Uma relação que se amplia: fotografia e ciência sobre e na Amazônia. In: KAWHAGE, C.; RUGGERI, S. (Org). Imagens e pesquisa na Amazônia: ferramentas de compreensão da realidade amazônica. Belém: Alves Gráfica e Editora, 2007b. p. 15-52. Ilustrado.

SIMONIAN, L.T.L. Pesquisa em ciências humanas e desenvolvimento entre populações tradicionais amazônicas. Boletim do Museu Paraense Emílio Goeldi, Belém, v. 1, n. 2, p. 119-134, maio/ago 2005. 
SIMONIAN, L.T.L. Políticas públicas, desenvolvimento sustentável e recursos naturais em áreas de reserva na Amazônia brasileira. In: COELHO, M.C.N.; SIMONIAN, L.; FENZL, N. (Org.). Estado e políticas públicas na Amazônia: gestão de recursos naturais. Belém: CEJUP: UFPA-NAEA, 2000. p. 09-53.

SOUZA, C. Estado da arte da pesquisa em políticas públicas. In: HOCHMAN, G.; ARRETCHE, M.; MARQUES, E. (Org.). Políticas públicas no Brasil. Rio de Janeiro: FIOCRUZ, 2007. p. 65-86.

SOUZA, C. Políticas públicas: uma revisão da literatura. Sociologias, Porto Alegre, ano 8, n. 16, p. 20-45, jul./dez. 2006.

SOUZA, M.L. Mudar a cidade: uma introdução crítica ao planejamento e à gestão urbanos. 4 ed. Rio de Janeiro: Bertrand Brasil, 2006a.

SOUZA, M.L. A prisão e a ágora: reflexões em torno da democratização do planejamento e da gestão das cidades. Rio de Janeiro: Bertrand Brasil, 2006b.

SRIDHARAN, S. Introduction to special section on "What is a Useful Evaluation?". American Journal of Evaluation, v. 24, n. 4, p. 483-487, 2003. Disponível em: <http://aje.sagepub.com>. Acesso em: 22 ago. 2007.

THÉRET, B. As instituições entre as estruturas e as ações. Lua Nova, [s.I.], n. 58, p. 225-254, 2003.

VIDAL, J.P. A realidade social é externa ao individuo? Uma aproximação à pesquisa qualitativa. Papers do NAEA, Belém, NAEA, n. 203, p. 1-24, 2006.

YIN, R.K. Estudo de caso: planejamento e métodos. 3. ed. Porto Alegre: Bookman, 2005.

Obs: Este artigo é derivado de dissertação de mestrado.

\section{Notas:}

1 Em 1991, é transformada de empresa para autarquia, pelo então presidente Fernando Collor de Melo, passando a denominação de Instituto Brasileiro de Turismo (EMBRATUR).

2 São os integrantes e/ou representantes da iniciativa privada, setor público e sociedade civil organizada, interessados e/ou beneficiários no processo de planejamento bem como nas políticas públicas de turismo/ecoturismo, em especial, neste caso, o PROECOTUR.

${ }^{3}$ Estudo coordenado pela norueguesa Gro Harlem Brundtland foi publicado em 1987 ficando conhecido, também, como Relatório Brundtland.

${ }^{4}$ Expressão americana para prestação de contas ao público.

${ }^{5}$ Aqui envolvendo a sociedade civil, o poder público e a iniciativa privada.

6 Entendida neste trabalho como compreendendo os integrantes e/ou representantes da sociedade civil organizada e a iniciativa privada. 
7 Belém, Curuçá, Marapanim, Maracanã, São João de Pirabas, Salinópolis, Tracuateua, Bragança, Augusto Corrêa e Viseu.

8 Que congrega os municípios de Augusto Corrêa, Belém, Bragança, Curuçá, Maracanã, Marapanim, Salinópolis, São João de Pirabas, Tracuateua e Viseu.

9 Que eram: plano de trabalho, "Diagnóstico do Potencial Ecoturístico do polo Belém/Costa Atlântica" e as "Estratégias para o Desenvolvimento do Ecoturismo no polo Belém/Costa Atlântica".

10 Três meses, contados a partir da assinatura do contrato.

11 Integrantes da UGP à época e que ocupavam, respectivamente, as funções de coordenador geral do PROECOTUR, gerente técnica e gerente de capacitação do PROECOTUR.

12 Denominação dada ao documento.

${ }^{13}$ Uma das autoras deste artigo estava presente na referida oficina.

Vânia Lúcia Quadros Nascimento: Universidade Federal do Pará, Belém, PA, Brasil.

E-mail: vluciaquadros@yahoo.com.br

Link para o currículo Lattes: http://lattes.cnpq.br/1887894972158078

Ligia Terezinha Lopes Simonian: Universidade Federal do Pará, Belém, PA, Brasil.

E-mail: simonianl@gmail.com

Link para o currículo Lattes: http://lattes.cnpq.br/6620574987436911

Data de submissão: 26 de dezembro de 2013

Data de recebimento de correções: 31 de julho de 2014

Data do aceite: 07 de agosto de 2014

Avaliado anonimamente 